\title{
Practice Must Be Backed up by Theory! A Special Issue on Plant Community Ecology
}

\author{
Giovanni Bacaro ${ }^{1}\left[\right.$ (), Simona Maccherini ${ }^{2, *}$ (i) and Michela Marignani ${ }^{3}$ (C) \\ 1 Department of Life Sciences, University of Trieste, Via L. Giorgieri 10, 34127 Trieste, Italy; gbacaro@units.it \\ Department of Life Sciences, University of Siena, Via P.A. Mattioli 4, 53100 Siena, Italy \\ 3 Department of Life and Environmental Sciences, Botany Division, University of Cagliari, Viale S. Ignazio, \\ 13, 09123 Cagliari, Italy; marignani@unica.it \\ * Correspondence: simona.maccherini@unisi.it
}

Received: 15 November 2020; Accepted: 16 November 2020; Published: 21 November 2020

\section{Introduction}

Plant communities form the structural and functional basis for nearly all terrestrial ecosystems [1]. Plant community ecology, then, relies on the study of the organization and functioning of plant communities: it includes the study of the interactions between species, the evolutionary pathways of adaptation to the environment where plants live, and the dynamics and structure of the community. This discipline is based on common definitions and analytical methodologies that date back decades.

This Special Issue (hereafter SI) presents a series of articles debating the modern concept of plant communities, both from a theoretical and an applied point of view, basing the selected papers on the concept that if practice is not backed up by theory, erroneous results can be produced. The issue brings together a collection of eight valuable articles that can be used as references for innovative ideas and as a starting point for the future development of the discipline. By a complete overview of the SI, it clearly emerges that there is, at the present time, a growing awareness among plant ecologists of the need to place their science on a more exact basis. The impetus given by the pioneers of ecology, which led to rapid advances in the past, is dying down, and the emphasis is changing from extensive work on vegetation to intensive work on selected aspects. On the one hand the need for improved techniques are made all the more urgent by the rapid depletion of natural vegetation, the only source of data on many of the more fundamental aspects of plant community ecology, and on the other hand by the realization that advances in many research branches depend upon answers to ecological questions. The analysis of the published articles in this SI also highlights that plant ecologists are fully aware of the value of the quantitative approach and of the valuable tools available in the techniques of statistical analysis and remote sensing approach. Nonetheless, faced with the rapidly expanding literature on new cutting-edge quantitative methods in ecology, there is a need for an assessment of the practical potentialities of these proposed techniques. This SI attempts to make such an assessment, although only partially, and it is hoped that any plant ecologist facing a particular problem will find guidance here on the most profitable means of obtaining and handling data, as well as a broad survey of the approaches available in plant community ecology.

The SI collected articles focus on the whole communities, rather than a single species. Even if heterogeneous in terms of approaches and issues, the papers share cross-cutting issues dealing with the importance of the community approach and the variation that we can observe by changing the scale of observation. The SI is articulated around three main topics, following the intrinsic nature of the articles presented: one related to more theoretical approaches applied to plant community analyses (methods), and the others dedicated to the practical side of applied plant community studies, i.e., conservation, and present (and future) global threats and challenges. 


\section{Methods (Theory)}

Robust survey methods are essential elements for every successful conservation action [2]. To challenge our comprehension of plant communities, we need to test strategies and hypotheses (e.g., environmental filtering hypothesis vs. niche divergence, [3]). The adoption of standardized methods and protocols to analyse data allowed us to untangle and describe the general successional trajectories of chronosequence studies in the Alps' glacier forelands [4]. Nevertheless, we must recognize that since new methods are continuously proposed in modern plant community ecology studies, we can benefit from the integration of new instruments with long consolidated, traditional approaches. The results of Pesaresi et al. [5] confirm that by using phenological behaviors described by NDVI time series, it is possible to separate and distinguish plant communities in an objective/instrumental way, thus overcoming the subjectivity intrinsic to the phytosociological method. In the same way, databases that allow classical floristic data to converge in big data sets are useful to understand and describe the big picture of the ecoregions [6].

\section{Conservation (Practice)}

Even though plants are critical to sustaining all life on Earth, they are increasingly subjected to different threats [7]. The pressure that humans exert on plants is at an unprecedented level and may push the planet beyond safe limits [8]. The Plant Conservation Report 2020 illustrates the progress towards the Global Strategy for Plant Conservation 2011-2020; however, despite the notable progress, significant tasks in plant conservation remain to be addressed [9]. Conservation requires a thorough knowledge of the spatial distribution of biodiversity, and this is still a work in progress for taxa such as cryptogams and lichens. Congruence across taxa has been proved as an effective tool to provide insights into the processes structuring the spatial distribution of taxonomic groups and it is useful for conservation purposes; yet, only a few studies on cross-taxon congruence have focused on the relationships among vascular plants and other groups [10,11]. In this SI, Marignani et al. [12] estimate the congruence pattern between vascular plants and bryophytes' diversity in a coastal sand dune system, together with the assessment of the effects of the occurrence of invasive alien species on the two taxa. Despite a certain congruence between species composition of vascular plant and bryophyte communities, the presence of invasive alien species negatively affected only bryophytes. This aspect shows how much there is still to be discovered on the topic of taxon congruence for habitat conservation. Linked with this topic, Martellos et al. [6] describe, through a GIS-based analysis, the main patterns of richness, functional traits and ecological requirements in 9 ecoregions in Italy of another neglected taxon: lichens. An outline of the main distribution patterns of lichens in Italy's ecoregions can provide a baseline for further advancements in the understanding of species richness and community composition of Italian lichens at a regional scale.

In plant conservation topics, the preservation of agrobiodiversity is becoming increasingly popular. Since the 1990s, due to the promotion of the concept of sustainable agriculture, the importance of wild plants growing on fields has been underlined; they have started to be perceived not only as competitors to arable crops but also as an element that increases the biodiversity in agroecosystems [13]. The pattern of co-occurrence of rare and threatened arable species is a topic not yet investigated. Fanfarillo et al. [14], in an analysis of winter arable vegetation of Italy, found that species of conservation interest tend to occur in the same community and that their presence can potentially be used as bioindicators of sites with high conservation value.

Monitoring plant assemblages is essential to assess ecosystem health and change. Sampling size is central for data precision and is often an overlooked element in sampling design [15]. Maccherini et al. [2] propose the application of a methodological approach based on the calculation of a measure of variability called pseudo-multivariate dissimilarity-based standard error (MultSE) [16] applied to describe the different habitats of the coastal sand dune systems in three Special Areas of Conservation (SACs) in Tuscany, Italy. The study showed that the minimum number of replicates needed to assess differences among habitats varied between 10 and 25. This approach can be used 
to develop cost-effective monitoring programs, useful to plant ecologists and biodiversity managers, to sample the main characteristics of plant assemblages in order to assess the conservation status of European habitat types in the Natura 2000 network.

\section{Global Threats and Challenges}

Recognizing a strong and necessary link between theory and practice is increasingly crucial if we consider that our disciplines are called upon to address issues of global interest [17].

Challenging our comprehension of the mechanisms that underlie the invasibility of Invasive Alien Species (IAS) can help us to cope with this key threat to biodiversity [18]. In particular, Tordoni et al. [3] suggested that functional niche divergence may foster community invasibility; resident native communities more susceptible to invasion are those which, on average, showed a combination of functional traits (higher resource acquisition capacity and lower drought resistance) coupled with an apparently reduced water-use efficiency. In a similar way, land-use change can trigger processes that transform the landscape [17]: land abandonment in sub-Mediterranean grasslands causes the spread of native tall-grasses, affecting biodiversity and ecosystem functioning [19]. At a fine scale, mowing is used to allow the recovery of the coenological composition after invasion, acting as an abiotic filter (enhancement of tolerance-avoidance strategies); the reduction of weaker competitors increases the functional variation between coexisting species. Understanding the mechanism that enhances the extent of functional strategies related to resource acquisition and storage, reproduction, space occupation, and temporal niche exploitation [19-21] can help us to answer global challenges.

Climate changes alter the composition of communities and the functioning of ecosystems across the globe [22]. Investigating the links between biodiversity and ecosystem functioning across spatial scales and rapid global change is a priority to identify management responses that will retain diverse, functioning systems. Fickert [4] employs a chronosequence approach, which assumes a temporal sequence in vegetation development by spatially different sites, ranging from the Eastern to Western Alps, regarding the time since deglaciation. The chronosequences cover a time span ranging between the maximum glacier extent in around 1850 and the current glacier terminus. The comparative examination proved the existence of several common patterns in primary succession, but also diverging successional trajectories from West to East. While the pioneer stage in all glacier forelands is similar both floristically and structurally, in the westernmost study site, the late-successional stage is shrub-dominated throughout, while herb-grass-dwarfshrub dominated throughout the easternmost study site. As development towards shrub-dominated vegetation is faster in the West, it can be expected that the shrub phase will replace the herb-grass-dwarfshrub phase currently still present in the glacier forelands to the East in the decades to come, a process probably accelerated by ongoing climate warming. The footprint of climate change can be perceived in plant successions, influencing plant assemblages in time.

\section{Final Remark}

In conclusion, our experience in collecting and analyzing the contributions of the many Authors who joined the discussion proposed in this SI, was an exciting activity with positive and interesting outcomes. The main message we conveyed is that to be consistent, plant communities' studies need to be based on solid theoretical foundations, using reproducible methods and standard approaches.

We are aware that this SI does not cover all the important topics that, nowadays, are discussed in the field of plant community ecology; nonetheless, we are also certain that the next generation of plant ecologists will provide us with the greatest advances in the study of plant communities and their ecology. These plant ecologists will experiment on nature using new accurate field techniques, remote sensing data and computer technologies, guided by more defined theoretical frameworks. The more frequent use of investigation tools such as multiscale sampling, better-replicated studies and the collection of detailed ancillary data integrated with improved GIS -based models, will increase 
our ability to interpret multiple patterns of plant diversity and understand the baseline mechanism of plant community ecology, from local to global scales. Most of our work lies ahead.

Funding: For this research MM was funded by Fondazione Banco di Sardegna e Regione Autonoma della Sardegna, L7/07, grant number DGR 28/21 of 17.05.2015.

Acknowledgments: We would like to thank all the authors for their contribution to this SI; our thanks go to the staff members at the MDPI editorial office for their support, with a special mention to Wei Zhang.

Conflicts of Interest: The authors declare no conflict of interest.

\section{References}

1. Partel, M.; Chiarucci, A.; Chytri, M.; Pillar, V.D. Mapping plant community ecology. J. Veg. Sci 2017, 28 , 1-3. [CrossRef]

2. Maccherini, S.; Bacaro, G.; Tordoni, E.; Bertacchi, A.; Castagnini, P.; Foggi, B.; Gennai, M.; Mugnai, M.; Sarmati, S.; Angiolini, C. Enough Is Enough? Searching for the Optimal Sample Size to Monitor European Habitats: A Case Study from Coastal Sand Dunes. Diversity 2020, 12, 138. [CrossRef]

3. Tordoni, E.; Petruzzellis, F.; Nardini, A.; Bacaro, G. Functional Divergence Drives Invasibility of Plant Communities at the Edges of a Resource Availability Gradient. Diversity 2020, 12, 148. [CrossRef]

4. Fickert, T. Common Patterns and Diverging Trajectories in Primary Succession of Plants in Eastern Alpine Glacier Forelands. Diversity 2020, 12, 191. [CrossRef]

5. Pesaresi, S.; Mancini, A.; Casavecchia, S. Recognition and Characterization of Forest Plant Communities through Remote-Sensing NDVI Time Series. Diversity 2020, 12, 313. [CrossRef]

6. Martellos, S.; d'Agostino, M.; Chiarucci, A.; Nimis, P.L.; Nascimbene, J. Lichen Distribution Patterns in the Ecoregions of Italy. Diversity 2020, 12, 294. [CrossRef]

7. Bachman, S.P.; Lughadha, E.M.N.; Rivers, M.C. Quantifying progress toward a conservation assessment for all plants. Conserv. Biol. 2018, 32, 516-524. [CrossRef]

8. Steffen, W.; Broadgate, W.; Deutsch, L.; Gaffney, O.; Ludwig, C. The trajectory of the Anthropocene: The great acceleration. Anthropocene Rev. 2015, 2, 81-98. [CrossRef]

9. Sharrock, S. Plant Conservation Report 2020: A Review of Progress in Implementation of the Global Strategy for Plant Conservation 2011-2020; Technical Series No. 95; Secretariat of the Convention on Biological Diversity: Montréal, QC, Canada; Botanic Gardens Conservation International: Richmond, UK, 2020; 68p.

10. Bacaro, G.; Tordoni, E.; Martellos, S.; Maccherini, S.; Marignani, M.; Muggia, L.; Petruzzellis, F.; Napolitano, R.; Da Re, D.; Guidi, T.; et al. Cross Taxon Congruence Between Lichens and Vascular Plants in a Riparian Ecosystem. Diversity 2019, 11, 133. [CrossRef]

11. Barbato, D.; Perini, C.; Mocali, S.; Bacaro, G.; Tordoni, E.; Maccherini, S.; Marchi, M.; Cantiani, P.; De Meo, I.; Bianchetto, E.; et al. Teamwork makes the dream work: Disentangling cross-taxon congruence across soil biota in black pine plantations. Sci. Total Environ. 2019, 656, 659-669. [CrossRef]

12. Marignani, M.; Lussu, M.; Murru, V.; Bacaro, G.; Cogoni, A. Effect of Invasive Alien Species on the Co-Occurrence Patterns of Bryophytes and Vascular Plant Species-The Case of a Mediterranean Disturbed Sandy Coast. Diversity 2020, 12, 160. [CrossRef]

13. Marshall, E.J.P.; Brown, V.K.; Boatman, N.D.; Lutman, P.J.W.; Squire, G.R.; Ward, L.K. The role of weeds in supporting biological diversity within crop fields. Weed Res. 2003, 43, 77-89. [CrossRef]

14. Fanfarillo, E.; Latini, M.; Abbate, G. Patterns of Co-occurrence of Rare and Threatened Species in Winter Arable Plant Communities of Italy. Diversity 2020, 12, 195. [CrossRef]

15. Marignani, M.; Del Vico, E.; Maccherini, S. Spatial scale and sampling size affect the concordance between remotely sensed information and plant community discrimination in restoration monitoring. Biodivers. Conserv. 2007, 16, 3851-3861.

16. Anderson, M.J.; Santana-Garcon, J. Measures of precision for dissimilarity-based multivariate analysis of ecological communities. Ecol. Lett. 2015, 18, 66-73. [CrossRef] [PubMed]

17. Franklin, J.; Serra-Diaz, J.M.; Syphard, A.D.; Regan, H.M. Global change and terrestrial plant community dynamics. Proc. Natl. Acad. Sci. USA 2016, 113, 3725-3734. [CrossRef] [PubMed] 
18. Liccari, F.; Castello, M.; Poldini, L.; Altobelli, A.; Tordoni, E.; Sigura, M.; Bacaro, G. Do Habitats Show a Different Invasibility Pattern by Alien Plant Species? A Test on a Wetland Protected Area. Diversity 2020, 12, 267. [CrossRef]

19. Bricca, A.; Tardella, F.; Tolu, F.; Goia, I.; Ferrara, A.; Catorci, A. Disentangling the Effects of Disturbance from Those of Dominant Tall Grass Features in Driving the Functional Variation of Restored Grassland in a Sub-Mediterranean Context. Diversity 2020, 12, 11. [CrossRef]

20. Tordoni, E.; Petruzzellis, F.; Nardini, A.; Savi, T.; Bacaro, G. Make it simpler: Alien species decrease functional diversity of coastal plant communities. J. Veg. Sci. 2017, 30, 498-509. [CrossRef]

21. Chelli, S.; Marignani, M.; Barni, E.; Petraglia, A.; Puglielli, G.; Wellstein, C.; Acosta, A.T.R.; Bolpagni, R.; Bragazza, L.; Campetella, G.; et al. Plant-environment interactions through a functional traits perspective: A review of Italian studies. Plant Biosyst. 2019, 153, 853-869. [CrossRef]

22. Mokany, K.; Thomson, J.; Lynch, A.; Jordan, G.; Ferrier, S. Linking changes in community composition and function under climate change. Ecol. Appl. 2015, 25, 2132-2141. [CrossRef] [PubMed]

Publisher's Note: MDPI stays neutral with regard to jurisdictional claims in published maps and institutional affiliations.

(C) 2020 by the authors. Licensee MDPI, Basel, Switzerland. This article is an open access article distributed under the terms and conditions of the Creative Commons Attribution (CC BY) license (http://creativecommons.org/licenses/by/4.0/). 